\title{
Predictive biomarkers and tumor microenvironment in female genital melanomas: a multi-institutional study of 55 cases
}

\author{
Ying $\mathrm{Yu}^{1} \cdot \mathrm{Ka}-\mathrm{Yu} \mathrm{Tse}^{2} \cdot$ Horace H. Y. Lee ${ }^{1} \cdot \mathrm{Kin}^{-L o n g} \mathrm{Chow}^{1} \cdot$ Hing-Wai Tsang ${ }^{3} \cdot$ Richard W. C. Wong $^{4} \cdot$ \\ Elaine T. Y. Cheung ${ }^{5} \cdot$ Wah Cheuk $^{5} \cdot$ Victor W. K. Lee $^{6} \cdot$ Wai-Kong Chan $^{7}$. Alice S. T. Wong ${ }^{8} \cdot$ Herbert H. F. Loong ${ }^{9} \cdot$ \\ Karen K. L. Chan ${ }^{2} \cdot$ Hextan Y. S. Ngan ${ }^{2} \cdot$ Annie N. Y. Cheung ${ }^{1} \cdot$ Philip P. C. Ip (1) ${ }^{1}$
}

Received: 28 April 2019 / Revised: 11 July 2019 / Accepted: 11 July 2019 / Published online: 5 August 2019

(c) United States \& Canadian Academy of Pathology 2019

\begin{abstract}
Female genital melanomas are rare. At diagnosis, most affected patients have advanced disease. Surgery remains the primary treatment, and adjuvant therapy is largely ineffective. Recently, immune checkpoints and the mitogen-activated protein kinase pathway have been explored as treatment targets. However, evaluation of these biomarkers in genital melanomas is limited. We evaluated the clinicopathological features of 20 vulvar, 32 vaginal, and three cervical melanomas and assessed programmed cell death ligand 1 (PD-L1) expression, CD8 tumor-infiltrating lymphocyte density, mismatch repair proteins, VE1 immunohistochemistry, and KIT and BRAF mutations. The median age of the patients was 66 years, and median tumor sizes were 25, 30, and $20 \mathrm{~mm}$ for vulvar, vaginal, and cervical tumors, respectively. Mean mitotic figures were 18, 19, and 30 per $\mathrm{mm}^{2}$. Thirty-seven patients $(67 \%)$ had operable tumors. After a median follow-up of 15 months, only nine patients $(16 \%)$ were alive. Eight of the nine survivors did not have lymph node metastasis. Using 5\% as the threshold, PD-L1 expression was observed in $55 \%, 50 \%$, and $33 \%$ of vulvar, vaginal, and cervical tumors, respectively, when the Roche SP263 antibody was used and 20\%, 53\%, and 0\%, respectively, when the Dako 28-8 antibody was used. The median CD8 tumor-infiltrating lymphocyte density was significantly higher in vulvar/vaginal than cervical melanomas and correlated with PD-L1 expression. No cases exhibited loss of mismatch repair proteins. Five cases harbored KIT mutations, three of which were hotspots. BRAF $\mathrm{V} 600 \mathrm{E}$ mutation was not detected. Univariable analysis showed that tumor size greater than or equal to $33 \mathrm{~mm}$, mitotic figures of greater than or equal to 10 per $\mathrm{mm}^{2}$, lymph node metastasis, and low CD8+ tumor-infiltrating lymphocyte density were adverse prognostic factors. Thus, patients with genital melanomas have a poor prognosis, and evaluation of multiple biomarkers is necessary to identify patients who may benefit from immunotherapy or targeted therapy.
\end{abstract}

This study was presented in part at the Annual Meetings of the United States and Canadian Academy of Pathology $\left(107^{\text {th }}\right.$ meeting, Vancouver, BC and $108^{\text {th }}$ meeting, National Harbor, MD).

Supplementary information The online version of this article (https:// doi.org/10.1038/s41379-019-0345-2) contains supplementary material, which is available to authorized users.

Philip P. C. Ip

philipip@hku.hk

1 Department of Pathology, The University of Hong Kong, Hong Kong SAR, China

2 Department of Obstetrics and Gynaecology, The University of Hong Kong, Hong Kong SAR, China

3 Department of Paediatrics \& Adolescent Medicine, The University of Hong Kong, Hong Kong SAR, China

4 Department of Pathology, Pamela Youde Nethersole Eastern Hospital, Hong Kong SAR, China

\section{Introduction}

Malignant melanomas involving the female genital tract account for less than $3 \%$ of melanoma cases in women [1-5]. These tumors are aggressive, and affected patients usually

5 Department of Clinical Pathology, Queen Elizabeth Hospital, Hong Kong SAR, China

6 Department of Pathology, Tuen Mun Hospital, Hong Kong SAR, China

7 Department of Pathology, Hong Kong Sanatorium and Hospital, Hong Kong SAR, China

8 School of Biological Sciences, The University of Hong Kong, Hong Kong SAR, China

9 Department of Clinical Oncology, The Chinese University of Hong Kong, Hong Kong SAR, China 
have advanced disease at presentation, with overall poor prognosis [1-3, 6-9]. Even if surgically resectable, obtaining adequate surgical margins may be challenging. There is no standardized adjuvant treatment, and those available are relatively ineffective $[4,10]$. Targeted therapy and immunotherapy have been shown to be successful in cutaneous melanomas [11-13]. Genital melanomas have pathogenic mechanisms different from those of other melanomas, and reports on different biomarkers for predicting treatment responses are limited [4, 9].

Immune checkpoint inhibitors that block the programmed cell death-1 (PD-1)/programmed cell death ligand-1 (PD-L1) interaction have become invaluable for treating many malignancies [14-16]. However, few reports have described PD-L1 expression in genital melanomas, and the frequencies of expression among different subtypes, the relationships between expression and treatment responses, and survival rates in patients with or without PD-L1 expression are unclear [17-21]. Other potential biomarkers, such as tumor-infiltrating lymphocytes and microsatellite instability, may help to identify patients who may benefit from immune checkpoint inhibitors [22-24]. The presence of tumor-infiltrating lymphocytes has long been recognized as a favorable prognostic factor in patients with melanoma, and their presence in the tumor has been shown to correlate with PD-L1 expression [14, 19]. Thus, combined assessment of PD-L1 and tumor-infiltrating lymphocytes is expected to be more informative as it is a better representation of the tumor microenvironment and may guide the use of immune checkpoint inhibitors $[25,26]$. Regardless of origin, tumors showing high microsatellite instability or mismatch repair deficiency have been shown to respond to immune checkpoint inhibitors [27]. Although few melanomas have been reported to be high microsatellite instability [22, 28-30], the microsatellite status of genital melanomas is unknown.

The mitogen-activated protein kinase pathway is often dysregulated in melanomas, and hotspot mutations in $C$ KIT, NRAS, BRAF, and MEK have become targets for treatment [31-34]. Initial screening for tumors harboring the $B R A F$ V600E mutation may be performed by using immunohistochemistry with a specific VE1 monoclonal antibody [35]. Nevertheless, the frequency of $B R A F$ mutations in genital melanomas is low, and the usefulness of this antibody remains uncertain [36, 37].

In this study, we aimed to elucidate the clinicopathological features of a rare collection of genital tract melanomas and evaluate potential biomarkers, including PD-L1, CD8 + tumor-infiltrating lymphocytes, mismatch repair proteins, VE1 immunohistochemistry, and KIT hotspot and BRAF V600E mutations, that identify patients who may benefit from immune checkpoint inhibitors and/or anti$\mathrm{C}-\mathrm{KIT}$ and anti-BRAF targeted therapies.

\section{Materials and methods}

This was a multi-institutional study evaluating all available vulvar, vaginal, and cervical melanomas from five major hospitals in Hong Kong. Only cases with sufficient clinical information with follow-up and available formalin-fixed, paraffin-embedded blocks were included. Patients who had simultaneous or previous cutaneous melanomas were excluded. This study was approved by the Institutional Review Boards of all participating hospitals (HKU/HA HKW IRB: UW 16-1022).

\section{Clinical features}

For each case, the patient's age, presentation, gross features and size of the tumor, extent of involvement, and clinical or radiological evidence of lymph node or other metastases were noted. Mode of primary treatment and any postoperative adjuvant radiation and/or chemotherapy were recorded. Follow-up data were reviewed. For vulvar melanomas, a stage was assigned using the $8^{\text {th }}$ Edition of the American Joint Commission on Cancer (AJCC) staging system, as previously recommended $[38,39]$. Staging for vaginal melanoma is not recommended in the 8th Edition of the AJCC staging system and there is no existing AJCC staging system for cervical melanomas [6, 38, 39]. Therefore, staging for vaginal and cervical melanomas was not performed.

\section{Pathological features}

Histologically, the tumor cell types (epithelioid, spindle, or mixed), tumor thickness, ulceration, number of mitotic figures per $\mathrm{mm}^{2}$, and any lymphovascular space and perineural invasion were determined. The presence of tumorinfiltrating lymphocytes was determined by examination of hematoxylin and eosin-stained sections. Tumor-infiltrating lymphocytes were lymphocytes which were concentrated at the tumor-stromal interface. Quantification of tumorinfiltrating lymphocytes was further confirmed using immunohistochemistry. Clearance of resection margins was determined from the pathology report or by re-examination of histological sections.

\section{Immunohistochemistry}

Immunohistochemical studies were performed on large resected specimens in $69 \%$ of cases. Two vulvar, 13 vaginal, and two cervical melanomas could only be investigated with biopsy specimens because these patients had inoperable tumors. Staining was conducted on whole-mount formalin-fixed, paraffin-embedded sections in a laboratory accredited by the College of American Pathologists. Staining with Ventana PD-L1 SP263 (Roche, Switzerland) and 
PD-L1 IHC 28-8 pharmDx (SK005; Dako, Denmark) was performed using a Ventana BenchMark Ultra instrument (Roche) and Autostainer Link 48 (Agilent Dako, USA), respectively. The T-lymphocyte marker CD8 (C8/144B; Dako) was detected using a Leica Bond III stainer (Leica Camera AG, Germany), and the mismatch repair proteins mutL homolog 1 (MLH1; clone M1), mutS homolog 2 (MSH2; clone G219-1129), mutS homolog 6 (MSH6; clone SP93), and PMS1 homolog 2 (PMS2; clone A16-4) as well as anti-BRAF V600E (mouse monoclonal, clone VE1, 7904855) were detected using a Ventana BenchMark Ultra instrument (Roche). In order to distinguish true cytoplasmic staining from melanin, we used an ultraView Universal Alkaline Phosphatase Red Detection Kit (Ventana Medical Systems, USA) to detect BRAF V600E protein expression. Two clinical specimens of melanomas harboring the $B R A F$ V600E mutation were used as positive controls. For all other markers, benign tissue (a multi-tissue sausage block) and appropriate tumors were used as positive controls according to the manufacturers' recommendations.

PD-L1 evaluation was performed by pathologists who had completed training conducted by the manufacturers (for interpretation of Roche Ventana and Dako antibodies). Interpretation of immunohistochemical staining was performed under a multiheaded microscope during consensus sessions and with agreement on final results. Scoring was performed for tumor cells but not lymphoid cells. In each section, the presence of at least 100 tumor cells was confirmed. Tumor cells with circumferential or partial membranous staining were considered positive for PD-L1. Necrotic tumor cells and cytoplasmic tumor cell staining were excluded from scoring. The extent of staining was deduced by assessing the percentage of positively stained tumor cells in the entire section and stated as greater than or equal to $5 \%$ or $10 \%[17,19,20]$. To facilitate meaningful comparison with other studies, analyses were performed using a threshold of greater than or equal to 5\%. For tumorinfiltrating lymphocytes, nuclear staining for CD8 was considered positive. We adopted a simple, inexpensive, robust quantitative assessment for tumor-infiltrating lymphocytes count without the need for using sophisticated image analysis tools. An area with the highest density of tumor-infiltrating lymphocytes on a whole-mount tissue section was predetermined and marked. In this area, the absolute count of positive cells per high-power field $(x 40$ objective; 0.55 -mm field diameter; $0.24 \mathrm{~mm}^{2}$ ) was scored by three observers (YY, KLC, and PI). Counting was facilitated using a manual counter. The median scores of the three observers were calculated. A tumor was considered to have loss of mismatch repair protein expression when nuclear staining was absent for one or more antibodies targeting MLH1, PMS2, MSH2, and MSH6 in the presence of positively stained lymphoid cells in the background.
Anti-BRAF VE1 antibody staining was considered positive if there was unequivocal diffuse cytoplasmic staining in more than $66 \%$ of tumor cells. The intensity of staining for BRAF expression was determined to be negative, weak, medium, or strong. Assessment was carried out without knowledge of the mutational status.

\section{KIT and BRAF mutation analysis}

The same sections used for VE1 immunohistochemistry were used for analysis of KIT and BRAF mutations. Representative areas containing tumor cells were marked by pathologists. The target cells were microdissected from four or five $10-\mu \mathrm{m}$-thick sections using a sterile needle under a microscope at $\times 10$ magnification. DNA was extracted with a Qiagen QIAamp DNA FFPE Tissue Kit (Qiagen Corp., USA), and the concentration of DNA for each sample was determined using a NanoDrop spectrophotometer (Thermo Fisher Scientific, Inc., USA). All samples containing extracted DNA were determined to be of high quality (with an A260/A280 ratio of 1.8-2.0). Polymerase chain reaction was performed using primers designed to flank the exons of the KIT and BRAF genes (Supplementary Table 1). DNA (50 ng) was amplified by $100 \mathrm{nmol}$ forward and reverse primers in $25-\mu \mathrm{L}$ reactions in the presence of HotStarTaq Plus DNA polymerase (Qiagen Corp.). Polymerase chain reaction conditions were as follows: initial denaturation at $95^{\circ} \mathrm{C}$ for $10 \mathrm{~min}$; 40 cycles of $94^{\circ} \mathrm{C}$ for $30 \mathrm{~s}, 60^{\circ} \mathrm{C}$ for $1 \mathrm{~min}$, and $72{ }^{\circ} \mathrm{C}$ for $1 \mathrm{~min}$; and a final extension at $72{ }^{\circ} \mathrm{C}$ for $5 \mathrm{~min}$. Successful amplification was confirmed by gel electrophoresis. KIT and BRAF gene mutations were analyzed by Sanger sequencing. Polymerase chain reaction products $(1 \mu \mathrm{L})$ corresponding to exons in the KIT and BRAF genes were used for BigDye Termination bidirectional sequencing and sequenced on an Applied Biosystems 3730xl DNA Analyzer (Thermo Fisher Scientific Inc.). Results were analyzed using Chromas sequence analysis software.

Two melanomas with known BRAF V600E mutations served as positive controls, and two genital melanocytic cell lines, i.e., HMVII (cat. no. RCB0777; vaginal melanoma; RIKEN Cell Bank, Japan) and HEMa-LP (Thermo Fisher Scientific Inc.), with known mutation profiles (and absence of the BRAF V600E mutation) served as negative controls.

\section{Statistical analysis}

Clinicopathological variables among histological subtypes were analyzed using Student's $t$-tests and Chi-squared tests. Optimal cut-off values for continuous variables, such as size, thickness, and CD8 count, were determined by choosing maximum values of Youden's index obtained from receiver operating characteristic analysis. Disease-free survival was defined as the time interval from the date of primary treatment 
to the date of recurrence or last follow-up. Overall survival was defined as the time interval from the date of primary surgery to the date of death or being censored at the date of the last follow-up. Univariable and multivariable analyses were performed with Cox proportional hazards models, and $p$-values of less than 0.05 were considered to represent statistical significance. Survival curves for significant variables were generated using the Kaplan-Meier method. The interobserver reproducibility of the tumor-infiltrating lymphocytes count was evaluated with intraclass correlation coefficients. Agreement was expressed in terms of the following threshold values: less than 0.00 , no agreement; $0.00-0.20$, slight agreement; $0.21-0.40$, fair agreement; $0.41-0.60$, moderate agreement; $0.61-0.80$, substantial agreement; and 0.81-1.00, near-perfect agreement. The linear relationship between PDL1 score and CD8 tumor infiltrating lymphocytes was evaluated using Pearson's correlation coefficient. Analyses were performed with SPSS Statistics for Macintosh, Version 22.0 (IBM, USA).

\section{Results}

\section{Clinicopathological features of female genital tract melanomas}

Fifty-five genital melanomas (20 vulvar, 32 vaginal, and three cervical) were collected from the pathology archives of five major hospitals from a 22-year period between 1996 and 2018. All contributing pathologists confirmed the original diagnoses based on histology review and immunohistochemistry (S-100 protein, HMB45/melan-A). At the time the biopsies were collected, none of the patients had been treated with targeted therapy drugs or immune checkpoint inhibitors.

\section{Vulvar melanomas}

The median age of the 20 patients was 64 years. At the time of presentation, two patients (10\%) had inoperable tumors, and 11 patients $(55 \%)$ already had lymph node metastases. Ten patients were classified as stage IIIC, three-stage IIIB, six-stage IIC, and one stage IIB. Seventeen patients (85\%) underwent surgery (Table 1). The surgical margins were involved in seven of 17 (41\%) patients, three of whom $(43 \%)$ subsequently died of disease. Postoperative adjuvant radiation therapy was given to four patients, and adjuvant chemotherapy was given to three patients. The median tumor size was $25 \mathrm{~mm}$. Fifteen $(75 \%)$ tumors contained epithelioid tumor cells, and five (25\%) had mixed epithelioid and spindle cells (Fig. 1a, b). Melanin deposits were observed in each case. The mean mitotic figures count was 18 per $\mathrm{mm}^{2}$. The tumor thickness was $2-8 \mathrm{~mm}$ (median: 5 $\mathrm{mm}$ ), and ulceration was present in 14 tumors (70\%). Tumor-infiltrating lymphocytes were present in 17 cases (85\%; Fig. 1c, d). Three cases had lymphovascular space invasion, but none had perineural invasion. The clinical and pathological features are summarized in Table 1.

Follow-up ranged from 4 to 208 months (median: 29 months). Fourteen patients (70\%) developed recurrence and disease progression after a median of 15 months (range: 4-54 months). Metastases developed in the lungs $(n=4)$, brain $(n=1)$, brain and liver $(n=2)$, bone and liver $(n=2)$, pelvis $(n=1)$, and multiple organs $(n=4)$. From the final follow-up records, 13 patients died of disease, and one remained alive with disease. Six patients $(30 \%)$ were alive and with no evidence of disease. Notably, five of these six survivors did not have lymph node metastasis at initial diagnosis.

\section{Vaginal melanomas}

The median age of the 32 patients was 68 years. The most common presentation was abnormal vaginal bleeding (34\%) or masses (28\%). Two (6\%) had abnormal Pap smears. At the time of presentation, 13 patients $(40 \%)$ had inoperable tumors, eight of whom received palliative radiotherapy. Thirteen patients (41\%) already had lymph node metastases. Nineteen patients (59\%) underwent surgery (Table 2). The surgical margins were involved in nine of $19(47 \%)$ patients, seven of whom (78\%) subsequently died of disease. Postoperative adjuvant radiation therapy was given to eight patients, and adjuvant chemotherapy was given to four patients. The median tumor size was $30 \mathrm{~mm}$. Twenty tumors $(63 \%)$ were epithelioid in nature, four $(13 \%)$ contained spindle cells, and eight (25\%) were mixed. Melanin deposition was present in each case. The mean mitotic figures count was 19 per $\mathrm{mm}^{2}$. The assessable tumor thickness was 2-23 mm (median: $8 \mathrm{~mm}$ ), and ulceration was present in 27 tumors (84\%). Tumor-infiltrating lymphocytes were present in 10 cases (31\%). In tumors that were excised and assessable, lymphovascular space invasion, and perineural invasion were not identified. The clinical and pathological features are summarized in Table 2.

Follow-up ranged from 2 to 138 months (median: 12 months). Eighteen patients (70\%) developed recurrence after a median of 8 months (range: 1-102 months). Metastases developed in the pelvis $(n=4)$, lungs $(n=4)$, liver $(n=2)$, bone $(n=1)$, intestines $(n=1)$, and multiple organs $(n=6)$. At last follow-up, 30 patients $(94 \%)$ died of disease. The two survivors (Va3 and Va36) had tumors that were 20 and $25 \mathrm{~mm}$ in size, respectively, and these had invaded through the vaginal wall but without involvement of the pelvic wall. There was also no lymph node metastasis at initial diagnosis. Resection margins were involved in each of their excisions. Patient Va3 received adjuvant radiation therapy and developed a local recurrence at 


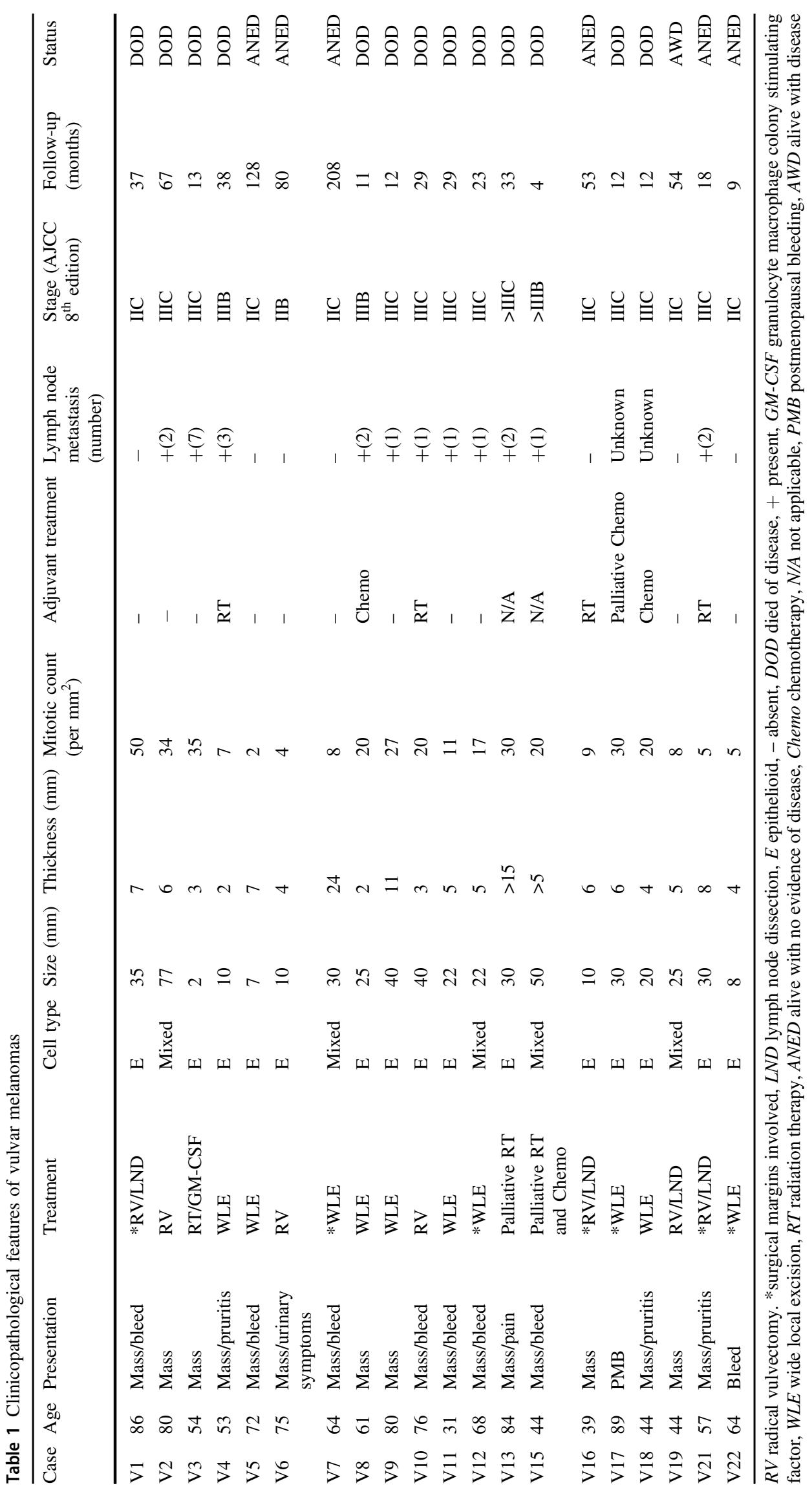


Fig. 1 Microscopic features and immunohistochemistry of genital melanomas. a Epithelioid tumor cells exhibit enlarged, oval nuclei and prominent nucleoli (hematoxylin and eosin). b Malignant melanomas with spindle cells show elongated and hyperchromatic nuclei (hematoxylin and eosin). c Melanoma with brisk tumorinfiltrating lymphocytes (hematoxylin and eosin). d Quantification of tumorinfiltrating lymphocytes using immunohistochemistry (antiCD8). e PD-L1

immunohistochemistry (Roche SP263). f PD-L1

immunohistochemistry (Dako 28-8). g Vulvar melanoma with weak cytoplasmic staining for VE1 antibody as assessed with an alkaline phosphatase red detection kit. This case did not have an underlying $B R A F$ V600E mutation. h Metastatic melanoma with known $B R A F$ V600E mutation with diffuse and strong cytoplasmic staining for VE1 as compared with that in $(\mathbf{g})$

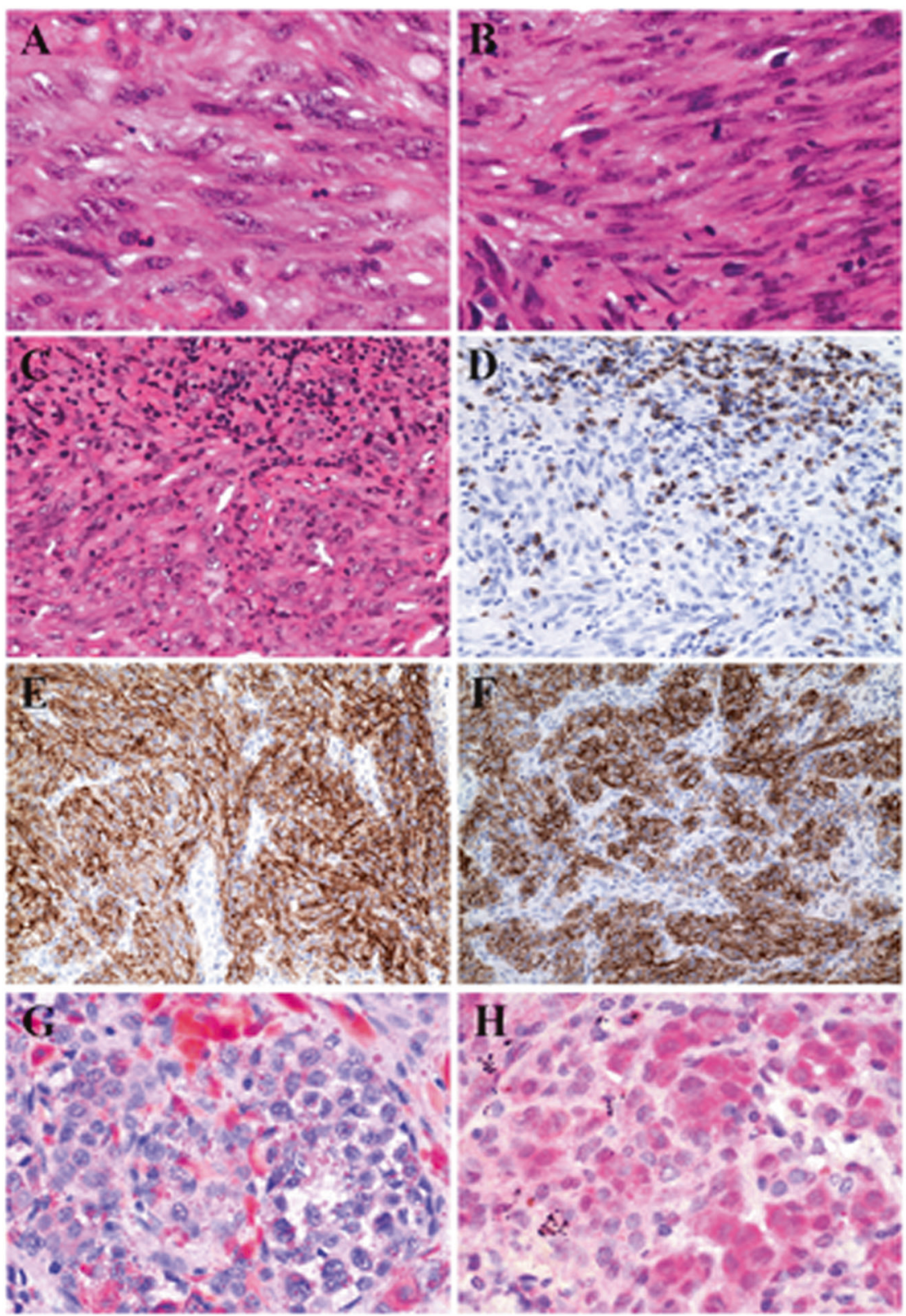

102 months. After re-excision, the patient was alive and without disease at 138 months. Patient Va36 had no adjuvant therapy, and local recurrence was discovered at 6 months. The patient was given radiation therapy and had no evidence of disease at 15 months.

\section{Cervical melanomas}

One of the three patients (C1) was asymptomatic, and the diagnosis was made during a routine Pap smear. As the tumor was confined to the cervix, she was treated with surgery, and the surgical margins were clear. Six courses of postoperative adjuvant radiation therapy were administered.
Follow-up at 6 months showed local recurrence and distant metastases involving the abdomen, bone, lungs, and brain. No additional treatment was given, and the patient died at 66 months. The other two patients had abnormal vaginal bleeding and cervical masses. At diagnosis, they both had advanced, inoperable disease treated with palliative radiation therapy (Table 3).

\section{Clinicopathological comparison between vulvar and non-vulvar melanomas}

Vulvar melanomas were more likely to present as an exophytic mass $(p=0.01)$, while vaginal and cervical 
Table 2 Clinicopathological features of vaginal melanomas

\begin{tabular}{|c|c|c|c|c|c|c|c|c|c|c|c|}
\hline Case & Age & Presentation & Treatment & Cell type & Size $(\mathrm{mm})$ & Thickness (mm) & $\begin{array}{l}\text { Mitotic } \\
\text { count } \\
\left(\text { per } \mathrm{mm}^{2}\right)\end{array}$ & $\begin{array}{l}\text { Adjuvant } \\
\text { treatment }\end{array}$ & $\begin{array}{l}\text { Lymph node } \\
\text { metastasis } \\
\text { (number) }\end{array}$ & $\begin{array}{l}\text { Follow-up } \\
\text { (months) }\end{array}$ & Status \\
\hline Val & 49 & Mass/bleed & *Excision & Mixed & 50 & 23 & 3 & - & $+(2)$ & 12 & DOD \\
\hline $\mathrm{Va} 2$ & 62 & Mass & *THBSO & $\mathrm{E}$ & 23 & 18 & 8 & RT & - & 46 & DOD \\
\hline Va3 & 71 & Mass & *WLE/ LND & E & 20 & 3 & 5 & RT & - & 138 & ANED \\
\hline Va4 & 79 & PMB & $* \mathrm{WLE}$ & E & 17 & 2 & 15 & - & Unknown & 10 & DOD \\
\hline Va5 & 72 & Mass/bleed & Palliative RT & E & 30 & 20 & 44 & N/A & $+(4)$ & 17 & DOD \\
\hline Va6 & 61 & PMB & Palliative RT & E & 50 & Unknown & 30 & N/A & $+(2)$ & 19 & DOD \\
\hline Va7 & 41 & Mass & Pelvic exent. & $S$ & 45 & 13 & 8 & RT & $+(1)$ & 10 & DOD \\
\hline Va8 & 80 & PMB & Palliative RT & E & 30 & 7 & 22 & N/A & - & 15 & DOD \\
\hline Va9 & 58 & PMB & None & E & 10 & 9 & 14 & - & Unknown & 14 & DOD \\
\hline Va10 & 69 & Mass/bleed & $* \mathrm{WLE}$ & Mixed & 30 & 18 & 38 & RT & - & 63 & DOD \\
\hline Va11 & 58 & PMB & Pelvic exent. & $\mathrm{E}$ & 60 & Unknown & 4 & Imatinib & $+(2)$ & 11 & DOD \\
\hline Va12 & 53 & Mass & Excision & S & 20 & 3.5 & 25 & Chemo & $+(1)$ & 12 & DOD \\
\hline Va13 & 59 & Mass & WLE/LND & E & 20 & Unknown & 10 & Chemo & $+(1)$ & 58 & DOD \\
\hline Va14 & 53 & Mass & Excision & S & 20 & 6 & 30 & Chemo & $+(1)$ & 12 & DOD \\
\hline Va15 & 72 & PMB & $* \mathrm{WLE}$ & E & 24 & 10 & 11 & Chemo & - & 127 & DOD \\
\hline Va16 & 53 & Mass & Excision & E & 20 & 7 & 8 & $\mathrm{RT}$ & $+(2)$ & 23 & DOD \\
\hline Va17 & 33 & $\begin{array}{l}\text { Vaginal } \\
\text { discharge }\end{array}$ & Palliative RT & E & 60 & 8 & 40 & N/A & $+(?)$ & 2 & DOD \\
\hline Va18 & 77 & PMB & Palliative RT & Mixed & 15 & 6 & 20 & N/A & - & 6 & DOD \\
\hline Va19 & 65 & $\begin{array}{l}\text { Abnormal } \\
\text { Pap smear }\end{array}$ & Pelvic exent. & Mixed & 30 & 9 & 18 & RT & $+(1)$ & 12 & DOD \\
\hline Va20 & 35 & $\begin{array}{l}\text { Vaginal } \\
\text { discharge }\end{array}$ & None & $S$ & 40 & 10 & 21 & - & Unknown & 8 & DOD \\
\hline Va21 & 66 & Mass/PMB & *THBSO & E & 25 & 11 & 16 & - & $+(2)$ & 12 & DOD \\
\hline Va23 & 80 & Mass/bleed & Palliative RT & E & 27 & 6 & - & N/A & Unknown & 10 & DOD \\
\hline Va24 & 87 & $\begin{array}{l}\text { Mass/urinary } \\
\text { symptoms }\end{array}$ & $*$ Excision & E & 35 & 20 & 12 & RT & Unknown & 29 & DOD \\
\hline Va25 & 73 & $\begin{array}{l}\text { Abnormal } \\
\text { Pap smear }\end{array}$ & Pelvic exent. & Mixed & 6 & 3 & 30 & - & $+(2)$ & 13 & DOD \\
\hline Va28 & 66 & $\begin{array}{l}\text { PMB/vaginal } \\
\text { discharge }\end{array}$ & Excision & Mixed & 45 & 15 & 28 & RT & - & 12 & DOD \\
\hline Va30 & 78 & $\begin{array}{l}\text { Mass/urinary } \\
\text { symptoms }\end{array}$ & Palliative RT & E & 30 & Unknown & 1 & N/A & Unknown & 28 & DOD \\
\hline Va31 & 88 & Mass & None & E & 50 & Unknown & 20 & - & Unknown & 6 & DOD \\
\hline Va32 & 85 & Mass/PMB & Excision & E & 20 & Unknown & 44 & - & - & 5 & DOD \\
\hline Va33 & 93 & Mass & None & E & 30 & 20 & 33 & - & Unknown & 6 & DOD \\
\hline Va34 & 74 & $\begin{array}{l}\text { Vaginal } \\
\text { discharge }\end{array}$ & Palliative RT & Mixed & 40 & 8 & 14 & N/A & Unknown & 9 & DOD \\
\hline Va35 & 86 & PMB & Palliative RT & Mixed & 30 & 20 & 19 & N/A & Unknown & 19 & DOD \\
\hline Va36 & 61 & PMB & $*$ WLE & $\mathrm{E}$ & 25 & 13 & 8 & - & - & 15 & ANED \\
\hline
\end{tabular}

*surgical margins involved, - absent, + present, DOD died of disease, THBSO total hysterectomy and bilateral salpingo-oophorectomy, $E$ epithelioid, $R T$ radiation therapy, $L N D$ lymph node dissection, ANED alive with no evidence of disease, $N / A$ not applicable, $P M B$ postmenopausal bleeding, WLE wide local excision, Pelvic exent. pelvic exenteration, Chemo chemotherapy

melanomas were significantly thicker $(p=0.02)$. Patients with vaginal and cervical melanomas were also significantly more likely to develop recurrence, exhibit disease progression with metastasis $(p=0.012)$, and die of the disease $(p=0.017)$ than patients with vulvar melanomas. The mortality rates were $65 \%(13 / 20)$ and $94 \%$ (33/35) for vulvar and non-vulvar melanomas, respectively. Age, gross pigmentation, tumor size, cell type, mitotic count, ulceration, necrosis, and presence of in-situ melanoma and melanin deposits were not significantly different between vulvar and non-vulvar lesions $(p>$ $0.05)$.

\section{Immunohistochemistry for PD-L1}

When the Roche Ventana SP263 antibody was used, greater than or equal to $5 \%$ staining was observed in $55 \%$ of vulvar, $50 \%$ of vaginal, and $33 \%$ of cervical melanomas. When the Dako 28-8 antibody was used, greater than or equal to $5 \%$ staining was observed in $20 \%$ of vulvar, $53 \%$ of vaginal, 
Table 3 Clinicopathological features of cervical melanomas

\begin{tabular}{|c|c|c|c|c|c|c|c|c|c|c|c|}
\hline Case & Age & Presentation & Treatment & $\begin{array}{l}\text { Cell } \\
\text { type }\end{array}$ & $\begin{array}{l}\text { Size } \\
(\mathrm{mm})\end{array}$ & $\begin{array}{l}\text { Thickness } \\
(\mathrm{mm})\end{array}$ & $\begin{array}{l}\text { Mitotic count } \\
\left(\text { per } \mathrm{mm}^{2}\right)\end{array}$ & $\begin{array}{l}\text { Adjuvant } \\
\text { treatment }\end{array}$ & $\begin{array}{l}\text { Lymph node } \\
\text { metastasis } \\
\text { (number) }\end{array}$ & $\begin{array}{l}\text { Follow-up } \\
\text { (months) }\end{array}$ & Status \\
\hline $\mathrm{C} 1$ & 49 & $\begin{array}{l}\text { Abnormal } \\
\text { Pap smear }\end{array}$ & THBSO, PLD & Mixed & 15 & 2 & 2 & RT & - & 66 & DOD \\
\hline $\mathrm{C} 2$ & 63 & Mass/bleed & RT & Mixed & 20 & $>6$ & 30 & - & $+(2)$ & 26 & DOD \\
\hline $\mathrm{C} 4$ & 85 & Mass/bleed & Palliative RT & Mixed & 40 & $>22$ & 40 & N/A & $+(1)$ & 16 & DOD \\
\hline
\end{tabular}

THBSO total hysterectomy and bilateral salpingo-oophorectomy, $P L D$ pelvic lymph node dissection, $R T$ radiation therapy, - absent, $D O D$ died of disease, + present, N/A not applicable

Table 4 PD-L1 staining and tumor-infiltrating lymphocytes density in genital melanomas

\begin{tabular}{llll}
\hline & Vulvar $(n=20)$ & Vaginal $(n=32)$ & Cervical $(n=3)$ \\
\hline PD-L1 (SP263), $\geq 5 \%$ & $11(55 \%)$ & $16(50 \%)$ & $1(33 \%)$ \\
PD-L1 (SP263), $\geq 10 \%$ & $8(40 \%)$ & $14(44 \%)$ & $1(33 \%)$ \\
PD-L1 (28-8), $\geq 5 \%$ & $4(20 \%)$ & $17(53 \%)$ & $0(0 \%)$ \\
PD-L1 (28-8), $\geq 10 \%$ & $2(10 \%)$ & $14(44 \%)$ & $0(0 \%)$ \\
CD8+ TIL (median) & $114 / \mathrm{hpf}$ & $127 / \mathrm{hpf}$ & $50 / \mathrm{hpf}$ \\
\hline
\end{tabular}

SP263 Roche Ventana SP263. 28-8, Dako 28-8, TIL tumor-infiltrating lymphocytes, $h p f$ high-power fields and $0 \%$ of cervical melanomas (Fig. 1e, f) (Table 4). The SP263 antibody detected more cases with positive staining among vulvar melanomas.

\section{Tumor-infiltrating lymphocytes density}

The median densities of CD8+ tumor-infiltrating lymphocytes in vulvar, vaginal, and cervical melanomas were 114, 127, and 50 per high-power field, respectively. During manual scoring of tumor-infiltrating lymphocytes using immunohistochemistry, close to complete agreement was noted among the three observers (intraclass correlation coefficient: $0.96 ; p<0.05)$. CD8+ tumorinfiltrating lymphocytes showed a significantly higher density among vulvar/vaginal melanomas than cervical melanomas $(p<0.05$; Fig. 1d). Using Pearson correlation analysis, CD8+ tumor-infiltrating lymphocytes counts were moderately positively correlated with a PD-L1 score greater than or equal to 5\% (Roche Ventana SP263), with a coefficient of $0.30(p<0.05)$. The relationships between PD-L1 expression and CD8+ tumor-infiltrating lymphocytes counts among different subtypes are shown in Table 5.

\section{KIT mutation}

Seven KIT mutations were found in five cases of vulvar and vaginal melanoma (Va10, Va17, Va18, Va36, and V22), but none were found in the three cervical melanoma cases. Three of the KIT mutations were hotspot mutations at exon 13 (Table 6).
Table 5 Tumor microenvironment according to PD-L1 expression and CD8+ tumor- infiltrating lymphocyte count (adapted from Teng et al. [25])

\begin{tabular}{ll}
\hline Type 1: PD-L1+, high TIL & Type 2: PD-L1-, low TIL \\
\hline 10 Vulvar & 3 Vulvar \\
7 Vaginal & 14 Vaginal \\
1 Cervical & \\
\hline Type 4: PD-L1-, high TIL & Type 3: PD-L1+, low TIL \\
\hline 6 Vulvar & 1 Vulvar \\
2 Vaginal & 9 Vaginal \\
2 Cervical & \\
\hline
\end{tabular}

TIL tumor-infiltrating lymphocytes

\section{BRAF (VE1) and mismatch repair protein expression}

Five vulvar and two vaginal melanomas showed diffuse and weak cytoplasmic staining for VE1 (Fig. 1g). None of the 55 cases of female genital tract malignant melanomas had abnormal mismatch repair protein expression.

\section{BRAF mutation}

In one vaginal melanoma ( $\mathrm{Va} 6$ ), a pathogenic mutation (F610I) was identified in exon 15 (COSM133631 c.1828 T $>A$ ) [40]. None of the 55 cases had BRAF V600E mutations, including seven cases in which immunohistochemical staining was diffuse and weak. Another vaginal melanoma (Va36) harbored four other mutations; however, these mutations were considered benign. 
Table 6 KIT and BRAF mutations in genital melanomas

\begin{tabular}{|c|c|c|c|c|}
\hline Gene & Sample & Position & Variation & Pathogenicity \\
\hline \multirow[t]{7}{*}{ KIT } & Va10 & Exon $13 *$ & $\begin{array}{l}\text { Rs121913512 } \\
\text { c. } 1924 \mathrm{~A}>\mathrm{G}, \\
\text { p.K642Q } \\
\text { HGMD: CM002803 } \\
\text { (associated with } \\
\text { GIST) COSM96871 }\end{array}$ & Pathogenic \\
\hline & Va17 & Exon 10 & $\begin{array}{l}\text { Novel mutation } \\
\text { c. } 1548 \mathrm{C}>\mathrm{T}\end{array}$ & - \\
\hline & Va18 & Exon $13^{*}$ & $\begin{array}{l}\text { c. } 1898 \mathrm{~A}>\mathrm{G}, \mathrm{p} . \mathrm{E} 633 \mathrm{G} \\
\text { COSM } 133765\end{array}$ & Pathogenic \\
\hline & \multirow[t]{2}{*}{ Va36 } & Intron 1 & $\begin{array}{l}\text { Rs } 999020 \\
\text { IVS1+56T>C }\end{array}$ & - \\
\hline & & Intron 17 & $\begin{array}{l}\text { Rs } 1008658 \\
\text { IVS17+78T }>C\end{array}$ & - \\
\hline & \multirow[t]{2}{*}{ V22 } & Exon $13 *$ & $\begin{array}{l}\text { rs121913512 } \\
\text { c.1924A>G, p.K642E } \\
\text { COSM1304 }\end{array}$ & Pathogenic \\
\hline & & Exon 14 & $\begin{array}{l}\text { c. } 2041 \mathrm{~T}>\mathrm{A}, \mathrm{p} . \mathrm{F} 681 \mathrm{I} \\
\text { COSM5581487 }\end{array}$ & Pathogenic \\
\hline \multirow[t]{4}{*}{$B R A F$} & Va6 & Exon $15^{*}$ & $\begin{array}{l}\text { COSM133631 } \\
\text { c. } 1828 \mathrm{~T}>\mathrm{A} \\
\text { p.F610I }\end{array}$ & Pathogenic \\
\hline & \multirow[t]{3}{*}{ Va36 } & Exon 7 & $\begin{array}{l}\text { Rs41282721 } \\
\text { IVS7+27G }>A\end{array}$ & - \\
\hline & & Intron 12 & $\begin{array}{l}\text { Rs62487918 } \\
\text { IVS13-48C >T }\end{array}$ & - \\
\hline & & $\begin{array}{l}\text { Exon and } \\
\text { Intron } 16\end{array}$ & $\begin{array}{l}\text { Rs9648696 } \\
\text { c. } 1920 A>G \\
\text { p.G643 } \\
\text { Rs3789806 } \\
\text { IVS16+16G>C }\end{array}$ & - \\
\hline
\end{tabular}

*Hotspot mutation, GIST gastrointestinal stromal tumor

\section{Survival analysis}

The median disease-free survival was 10 months and the median overall survival was 14 months. In univariable analysis, tumor size greater than or equal to $33 \mathrm{~mm}$, mitotic figures counts greater than or equal to 10 per $\mathrm{mm}^{2}$, presence of lymph node metastasis at the time of initial diagnosis, and CD8 + tumor-infiltrating lymphocytes count less than 113 per high-power field were adverse prognostic factors for diseasefree survival and overall survival (Fig. 2). PD-L1 expression had no prognostic significance (Table 7). In multivariable analysis, only mitotic counts greater than or equal to 10 per $\mathrm{mm}^{2}(p=0.04)$ was an adverse prognostic factor.

\section{Discussion}

Melanomas arising from the vulva, vagina, and cervix have a poor prognosis $[1,9,41,42]$. In this study, we evaluated the clinicopathological features and potential biomarkers of genital melanomas. Our results showed that $94 \%$ of patients with vaginal melanoma and $100 \%$ of patients with cervical melanoma died after median follow-up periods of 12 and 26 months, respectively, although only $65 \%$ of patients with vulvar melanoma succumbed to disease after a median follow-up of 29 months.

Diagnosis of malignant melanoma by initial Pap smear is uncommon [43, 44]. In our series, one cervical and two vaginal melanomas were detected by Pap smear. For other patients, presentation as a mass was more frequent in vulvar than in vaginal or cervical tumors (Fig. 3), whereas abnormal bleeding or discharge was a more common presentation for vaginal and cervical tumors than for vulvar tumors. Poor prognostic factors reported for genital melanomas include older age, black race, nonvulvar location, large tumor size, greater depth of invasion, presence of ulceration, high mitotic figures count, lymph node metastasis, and margin involvement [2, 3, 7, 9, 45-48]. In our series, age was not an adverse prognostic factor, but most patients were either peri- or postmenopausal (median age: 66 years), similar to an earlier Asian study [8]. We also found that tumor size greater than or equal to $33 \mathrm{~mm}$, nonvulvar location, mitotic figures count of greater than or equal to 10 per $\mathrm{mm}^{2}$, presence of lymph node metastasis at diagnosis, and low CD8+ tumor-infiltrating lymphocytes count were adverse prognostic factors, whereas cell type, lymphovascular space, and perineural invasion were not prognostic factors.

Because genital melanomas are rare, experience with these tumors is limited, and the primary goal is complete surgical resection. However, in clinical practice, most patients have advanced disease at presentation, and complete resection is not always possible [46, 47, 49, 50]. The choice of surgical procedure and observation of clear resection margins are thought to be important for prognosis [4]. Notably, in our study, these factors did not affect overall survival, possibly because many patients already exhibited lymph node or distant metastasis. Regional lymph node dissection has been recommended for patients with clinically apparent nodal disease [51]. Our results showed that absence of nodal metastasis at diagnosis was associated with a good prognosis $[9,10,49,52]$. Eight of the nine survivors in our study did not have lymph node metastasis at diagnosis and were alive after a median of 54 months. Sentinel lymph node dissection is now a standardized procedure for cutaneous melanomas and is recommended for tumors with a thickness of $1-4 \mathrm{~mm}$ [53]. However, most genital melanomas are thicker, as in our series in which the median thickness was greater than or equal to $5 \mathrm{~mm}$, and the value of sentinel lymph node mapping remains unclear. Owing to the rarity of genital melanomas, very few patients have been recruited for systemic therapy trials, and the benefits of adjuvant chemotherapy remain unclear $[10,54,55]$. Dacarbazine is often used either alone or in combination with vincristine, cisplatin/carboplatin, or nimustine $[4,45,56]$. Moreover, genital melanomas are 
A

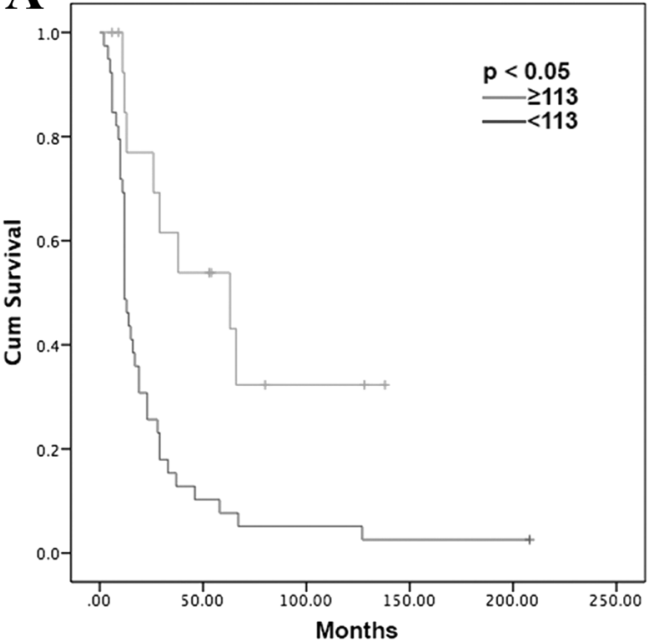

C

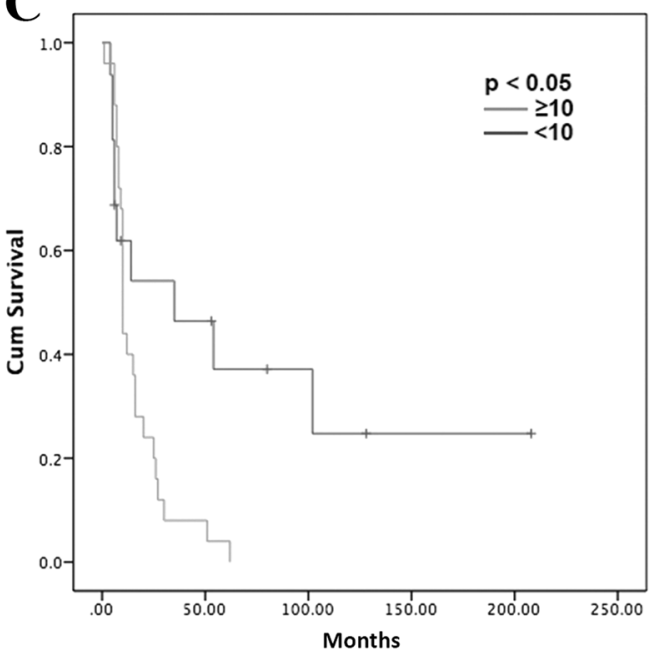

$\mathbf{E}$

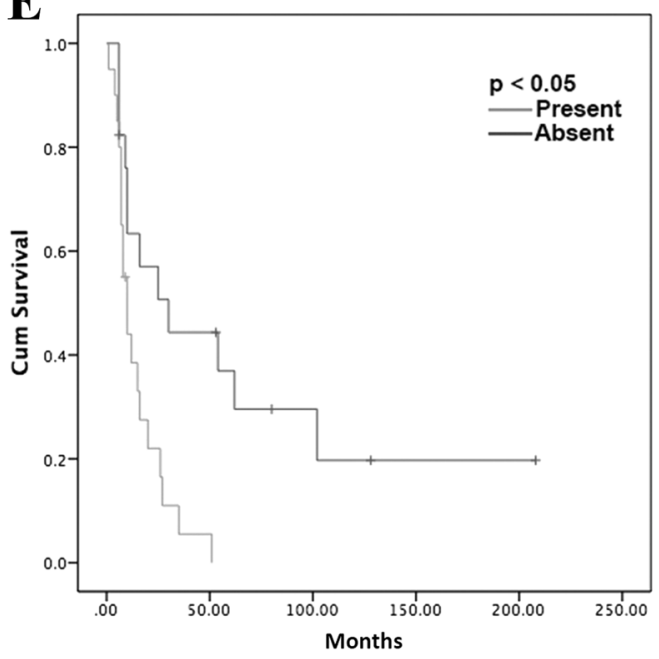

Fig. 2 Prognostic value of pathological parameters in genital melanomas. Kaplan-Meier plots indicating a disease-free survival and $\mathbf{b}$ overall survival of patients stratified by a cut-off value of 113 CD8+ tumor-infiltrating lymphocytes per high-power field. Kaplan-Meier plots indicating $\mathbf{c}$ disease-free survival and d overall survival of

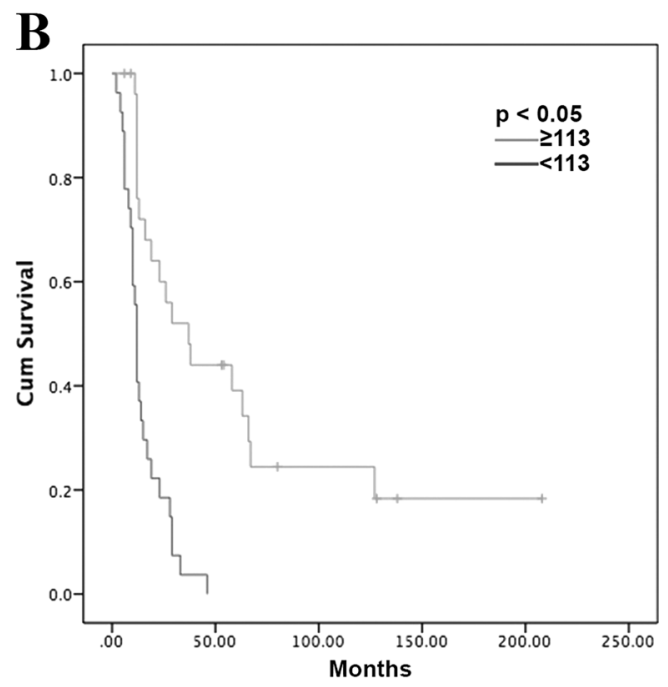

D

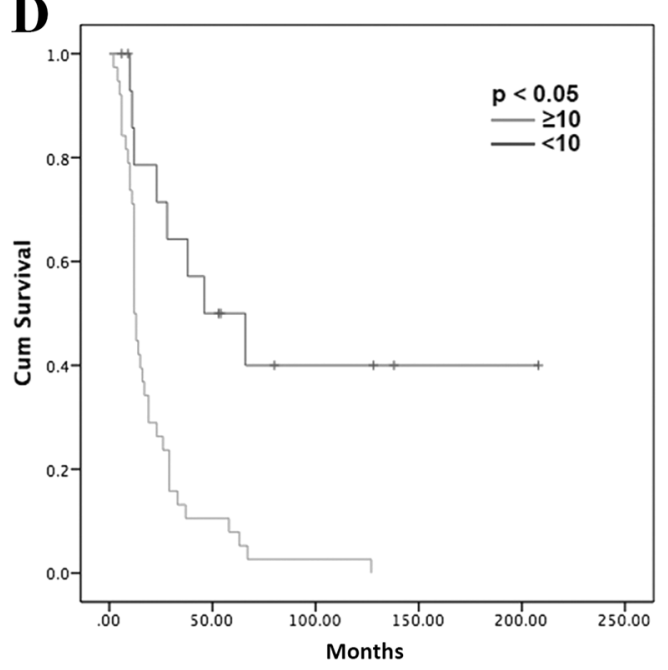

$\mathbf{F}$

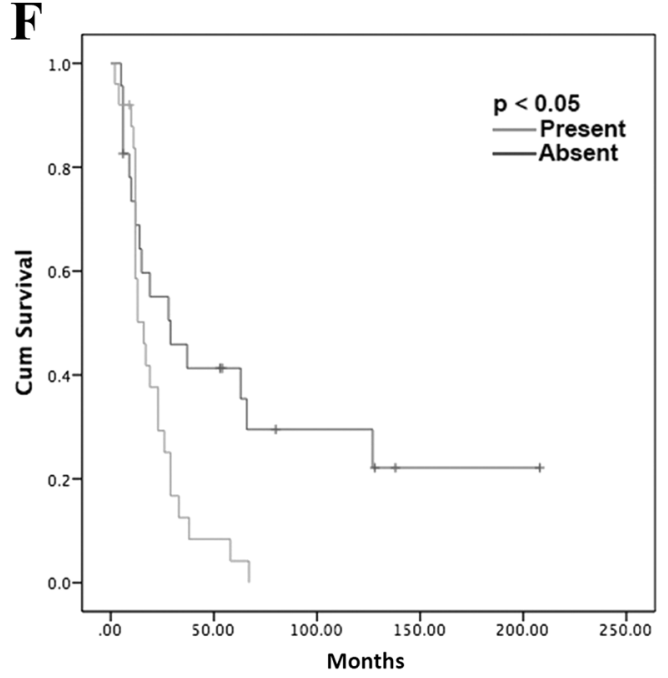

patients stratified by mitotic count per 10 per $\mathrm{mm}^{2}$. Kaplan-Meier plots indicating e disease-free survival and $\mathbf{f}$ overall survival of patients stratified by the presence or absence of lymph node metastasis at initial diagnosis 
Table 7 Univariable analysis of clinicopathological features of female genital melanomas

\begin{tabular}{|c|c|c|c|c|}
\hline \multirow[t]{2}{*}{ Univariable } & \multirow[t]{2}{*}{ Hazard ratio } & \multicolumn{2}{|c|}{$95.0 \% \mathrm{CI}$} & \multirow[t]{2}{*}{$p$-value } \\
\hline & & Lower & Upper & \\
\hline \multicolumn{5}{|l|}{ Size (mm) } \\
\hline$<33$ & 1.00 & - & - & - \\
\hline$\geq 33$ & 2.06 & 1.11 & 3.81 & $<0.05$ \\
\hline \multicolumn{5}{|l|}{ Thickness (mm) } \\
\hline$<7.9$ & 1.00 & - & - & - \\
\hline$\geq 7.9$ & 1.46 & 0.78 & 2.72 & 0.24 \\
\hline \multicolumn{5}{|c|}{ Mitotic figures (per $\mathrm{mm}^{2}$ ) } \\
\hline$<10$ & 1.00 & - & - & - \\
\hline$\geq 10$ & 3.88 & 1.77 & 8.51 & $<0.05$ \\
\hline \multicolumn{5}{|l|}{ Lymph node* } \\
\hline No & 1.00 & - & - & - \\
\hline Yes & 2.22 & 1.13 & 4.34 & $<0.05$ \\
\hline \multicolumn{5}{|l|}{ PD-L1 (SP263) } \\
\hline$<5 \%$ & 1.00 & - & - & - \\
\hline$\geq 5 \%$ & 0.90 & 0.50 & 1.62 & 0.72 \\
\hline \multicolumn{5}{|l|}{ PD-L1 (28-8) } \\
\hline$<5 \%$ & 1.00 & - & - & - \\
\hline$\geq 5 \%$ & 1.19 & 0.66 & 2.16 & 0.57 \\
\hline \multicolumn{5}{|c|}{ CD8+ TIL count } \\
\hline$<113$ per hpf & 1.00 & & & \\
\hline$\geq 113$ per hpf & 0.31 & 0.14 & 0.67 & $<0.05$ \\
\hline
\end{tabular}

CI confidence interval, $*$ presence of lymph node metastasis at initial diagnosis, TIL tumor-infiltrating lymphocytes, $h p f$ high-power fields

typically resistant to radiation therapy [57]. Before the era of immune checkpoint inhibitors, 13 patients in our series received postoperative adjuvant radiation, but only two survived. One study showed that the combination of radiotherapy and ipilimumab, a cytotoxic T-lymphocyte-associated protein 4 antagonist, was more effective than radiotherapy alone in treating lower genital tract melanomas [58].

In cutaneous melanomas, expression of PD-L1 in tumor cells is correlated with treatment response to immune checkpoint inhibitors and serves as a prognostic marker [24, 26, 59-63]. Although several reports have described PD-L1 expression in genital melanomas, direct comparisons among these studies are difficult to conduct because of the different antibody clones used and different cut-off scores [17-19]. This lack of comparative data indicates that there is currently no consensus with regard to a clinically relevant expression threshold for genital melanomas. Nevertheless, when a cut-off greater than or equal to $5 \%$ was used, our results were comparable to those reported in two other studies using the same parameter [17, 18] (Supplementary Table 2).

Currently, there are four anti-PD-L1 antibodies registered with the US Food and Drug Administration for use on two

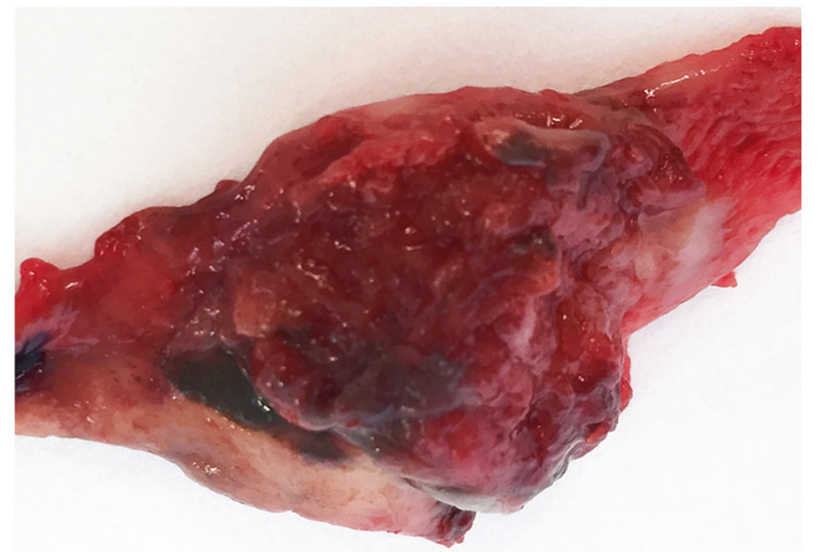

Fig. 3 Gross appearance of a malignant melanoma involving the female genital tract. This vaginal tumor has a polypoid exophytic surface component. Hemorrhagic fleshy areas alternate with ulceration. Black-brown pigmentation is prominent

different platforms (Dako 22C3 and 28-8 on Autostainer Link 48 and Roche SP263 and SP142 on Ventana BenchMark Ultra). Of the two clones tested, Roche SP263 identified more PD-L1-positive cases than Dako 28-8. This observation has also been noted in other studies [64]. The difference in positive staining may be related to the differences in the affinities of antibody binding to the protein (SP263 binds to the intracellular domain, and 28-8 binds to the extracellular domain) [65]. Tissue factors, such as spatial heterogeneity, may be of less relevance because consecutive sections from the same biopsy are used for both tests $[65,66]$. Recent data supporting the interchangeability of Dako 22C3, Dako 28-8, and Roche SP263 PD-L1 assays have been described, mostly in non-small cell lung cancers, with only one study addressing this issue in melanomas [65, 67]. Unfortunately, the number of cases in the latter study was only 34 , and whether any of the cases were of genital origin was unknown [65]. Although it is premature to draw any conclusions regarding the performance and interchangeability of these antibodies in genital melanoma, awareness of the choice of antibody used when treatment decisions are made is important.

The rarity of genital melanomas has resulted in difficulties in obtaining sufficient numbers of cases for largescale studies, and several clinical trials have grouped genital melanomas into the mucosal melanoma category. Accordingly, the significance of PD-L1 expression and responses of genital melanomas to anti-PD-1/PD-L1 therapies remain unclear [19, 20, 38, 68-70]. Nevertheless, regardless of the PD-L1 immunohistochemistry status, some genital melanomas have been shown to respond to immune checkpoint inhibitors [21,71]. The discordance between the absence of PD-L1 expression and drug responsiveness indicates that the use of PD-L1 immunohistochemistry as a single 
predictive marker may not be sufficient. Accordingly, other potential biomarkers should be investigated in combination with PD-L1 immunohistochemistry [22-24, 28].

Understanding the tumor microenvironment has become important in the era of cancer immunotherapy [72]. The presence of tumor-infiltrating lymphocytes has long been recognized as a favorable prognostic factor in melanomas [73], and higher quantities of tumor-infiltrating lymphocytes, particularly CD8+ cytotoxic $\mathrm{T}$ cells, have been shown to correlate with improved patient survival [74]. In our study, we demonstrated that a higher CD8+ tumorinfiltrating lymphocytes density was associated with longer survival in patients with genital melanomas. This finding was consistent with the results of other studies [19, 20]. In future studies, digital image analysis is expected to provide a more detailed characterization of immune cell profiles and functions [75].

The combined assessment of PD-L1 and tumorinfiltrating lymphocytes has been proposed to be useful for guiding treatment decisions [14, 25]. A subgroup of melanomas demonstrating adaptive immune resistance, characterized as PD-L1+/high tumor-infiltrating lymphocytes, was found to be responsive to immunotherapy $[15,24]$. Indeed, blocking of PD-L1 activity is thought to permit pre-existing high-density intratumoral cytotoxic $\mathrm{T}$ cells in the "hot" immune microenvironment to exert anticancer effects. In our study, 10 of 20 vulvar melanomas, seven of 32 vaginal melanomas, and one of three cervical melanomas were PD-L1+/high tumor-infiltrating lymphocytes (Table 5). Immune checkpoint inhibitors may be more effective for these patients [25]. Moreover, these "hot" melanomas were more often located in the vulva than in the vagina or cervix. Given the complexity of the tumor microenvironment, future studies are needed to evaluate other lymphoid cell elements for more precise patient selection.

The reported frequency of KIT mutations in genital melanomas ranges from 7 to $45 \%$; the frequency observed in our cases (14\%) falls within this range [32]. Among the reported pathogenic KIT mutations, seven gain-of-function mutations (V599D, V560D, L576P, D820V, D816V, V654A, and N822K) and one loss-of-function mutation (V555A) have been characterized in detail [76-78]. Tumors with V559D, V560D, and L576P mutations were shown to be more sensitive to the C-KIT inhibitors imatinib and sunitinib, whereas those with D820V, D816V, V654A, $\mathrm{N} 822 \mathrm{~K}$, and V555A mutations were associated with drug resistance [79-82]. Among our cases of genital melanoma, we discovered four pathogenic mutations: K642E, K642Q, E633G, and F681I. A previous report of K642E in a genital melanoma revealed that the mutated tyrosine kinase I domain resulted in a constitutively active conformation of the kinase [83]. In gastrointestinal stromal tumors, this mutation was associated with imatinib treatment response in both in vitro drug testing and patient treatment. K642Q, E633G, and F681I were reported in a gastrointestinal stromal tumor, an acral melanoma (from a Chinese patient), and a desmoplastic melanoma, respectively [84-86]. Whether these mutations render the tumors sensitive to C-KIT inhibitors requires further evaluation.

The BRAF V600E mutation accounts for $~ 90 \%$ of $B R A F$ mutations in cutaneous melanomas [87]. Targeting $B R A F$ V600E, an activating mutation, with tyrosine kinase inhibitors, such as vemurafenib and dabrafenib has been shown to be effective with significant survival benefits. The V600E mutation has occasionally been identified in a subset of genital melanomas (frequency: 6-23\%) [17, 88, 89]. The presence of this mutation may be reliably screened with immunohistochemistry using the specific antibody VE1, which targets the cytoplasmic protein [35, 90, 91]. However, melanin pigment present in tumors can make evaluation difficult, and an alkaline phosphatase-based red detection kit should be used. In our study, using this detection method, five vulvar and two vaginal melanomas showed diffuse $(>66 \%)$ but weak cytoplasmic staining. None of these cases were subsequently found to harbor the V600E mutation when analyzed by Sanger sequencing. Based on the low frequency of $B R A F \mathrm{~V} 600 \mathrm{E}$ mutations in genital melanomas, difficulties in immunohistochemical analysis, and the high cost of the VE1 antibody, this approach may not be a practical or informative screening tool. Molecular analysis should be considered instead. Incidentally, a pathogenic mutation (COSM133631 c.1828 $\mathrm{T}>\mathrm{A}$ ) previously reported in basal cell carcinoma of the skin [40] was discovered in one of the vaginal melanomas in our study.

Tumors with either mutations or epigenetic inactivation of mismatch repair genes (i.e., $M L H 1, M S H 2, M S H 6$, and $P M S 2)$ are considered microsatellite-high/mismatch repair deficient and cannot repair defects in DNA replication. These tumors are more prone to accumulate multiple genomic alterations, resulting in high mutational burden, increased neoantigen load, and increased tumor-infiltrating lymphocytes. These tumors have also been shown to be more responsive to immune checkpoint inhibitors [27, 92]. Screening for an underlying mismatch repair deficiency can be carried out using immunohistochemistry, and loss of staining for any of the mismatch repair proteins can be further verified with more detailed microsatellite instability tests. While the majority of analyses were performed with non-cutaneous and non-melanocytic tumors, a few cutaneous melanomas were reported to be microsatellite-high $[22,28-30,93]$. The status in genital melanomas is unclear. In our study, none of the cases showed loss of mismatch repair proteins, suggesting that microsatellite instability may be a rare event in genital melanomas and that 
immunohistochemistry may not be a useful biomarker for screening. However, microsatellite-high is more frequently detected in metastatic than in primary tumors in cutaneous melanomas because of acquisition of new mutations as the tumor progresses and disseminates [28]. Whether this occurs in metastatic genital melanomas is unknown.

In summary, melanomas of the vulva, vagina, and cervix are aggressive, and affected patients have a poor prognosis. In our study, we found that tumor size greater than or equal to $33 \mathrm{~mm}$, mitotic figures count of greater than or equal to 10 per $\mathrm{mm}^{2}$, the presence of lymph node metastasis at diagnosis, and low CD8+ tumor-infiltrating lymphocytes density were adverse prognostic factors. Surgery may not always be feasible, and conventional adjuvant therapy is ineffective. Evaluation of multiple biomarkers should be considered to identify patients suitable for targeted therapy and immunotherapy. Our study was limited by the small sample size for cervical melanomas. For patients who had inoperable tumors, the assessment of biomarkers was only feasible in biopsy specimens, which may have affected the accuracy of the results in some cases. The retrospective nature of the study was also an inherent limitation because treatment modalities have changed and evolved over the study period of 22 years. In future studies, next-generation sequencing may enable more thorough elucidation of potential therapeutic targets. While a minority of the tumors had KIT mutations, none had BRAF V600E mutations, and loss of staining for any of the mismatch repair proteins was not observed. A subset of patients whose tumors express PD-L1 and have higher density of tumor-infiltrating lymphocytes may benefit from immune checkpoint inhibitors.

Acknowledgements We thank Mr. and Mrs. Frankie Ko for their generous support. We are grateful to Ms. Kathy Cheung, Ms. Penny Wong, and Dr. Tsun-Yee Tsang for their kind assistance with key aspects of the project. We also thank Dr. Nafisa Wilkinson for her constructive comments.

\section{Compliance with ethical standards}

Conflict of interest The authors declare that they have no conflict of interest.

Publisher's note: Springer Nature remains neutral with regard to jurisdictional claims in published maps and institutional affiliations.

\section{References}

1. Ragnarsson-Olding B, Nilsson B, Kanter-Lewensohn L, Lagerlöf $\mathrm{B}$, Ringborg U. Malignant melanoma of the vulva in a nationwide, 25-year study of 219 Swedish females: predictors of survival. Cancer. 1999;86:1285.

2. Sugiyama VE, Chan JK, Shin JY, Berek JS, Osann K, Kapp DS. Vulvar melanoma: a multivariable analysis of 644 patients. Obstet Gynecol. 2007;110:296-301.
3. Weinstock MA. Malignant melanoma of the vulva and vagina in the United States: patterns of incidence and population-based estimates of survival. Am J obstet Gynecol. 1994;171:1225-30.

4. Leitao MM Jr, Cheng $X$, Hamilton AL, Siddiqui NA, Jurgenliemk-Schulz I, Mahner S, et al. Gynecologic Cancer InterGroup (GCIG) consensus review for vulvovaginal melanomas. Int J Gynecol Cancer. 2014;24:S117-S22.

5. Yin C, Yang A, Zhang Y, Tao L, Zou H, Ren Y, et al. Primary cervical malignant melanoma: 2 cases and a literature review. Int $\mathrm{J}$ Gynecol Pathol. 2019;38:196-203.

6. Gadducci A, Carinelli S, Guerrieri ME, Aletti GD. Melanoma of the lower genital tract: Prognostic factors and treatment modalities. Gynecol Oncol. 2018;150:180-9.

7. Gupta D, Malpica A, Deavers MT, Silva EG. Vaginal melanoma: a clinicopathologic and immunohistochemical study of 26 cases. Am J Surg Pathol. 2002;26:1450-7.

8. Khoo U, Collins R, Ngan H. Malignant melanoma of the female genital tract: a report of nine cases in the Chinese of Hong Kong. Pathology. 1991;23:312-7.

9. Mert I, Semaan A, Winer I, Morris RT, Ali-Fehmi R. Vulvar/ vaginal melanoma: an updated surveillance epidemiology and end results database review, comparison with cutaneous melanoma and significance of racial disparities. Int $\mathbf{J}$ Gynecol Cancer. 2013;23:1118-25.

10. Tcheung WJ, Selim MA, Herndon JE, Abernethy AP, Nelson KC. Clinicopathologic study of 85 cases of melanoma of the female genitalia. J Am Acad Dermatol. 2012;67:598-605.

11. Bradish JR, Montironi R, Lopez-Beltran A, Post KM, MacLennan GT, Cheng L. Towards personalized therapy for patients with malignant melanoma: molecular insights into the biology of BRAF mutations. Future Oncol. 2013;9:245-53.

12. Schadendorf D, Fisher DE, Garbe C, Gershenwald JE, Grob JJ, Halpern A, et al. Melanoma. Nat Rev Dis Prim. 2015;1:15003.

13. Cooper ZA, Juneja VR, Sage PT, Frederick DT, Piris A, Mitra D, et al. Response to BRAF inhibition in melanoma is enhanced when combined with immune checkpoint blockade. Cancer Immunol Res. 2014;2:643-54.

14. Taube JM, Anders RA, Young GD, Xu H, Sharma R, McMiller $\mathrm{TL}$, et al. Colocalization of inflammatory response with B7-h1 expression in human melanocytic lesions supports an adaptive resistance mechanism of immune escape. Sci Transl Med. 2012;4:127ra37.

15. Tumeh PC, Harview CL, Yearley JH, Shintaku IP, Taylor EJ, Robert L, et al. PD-1 blockade induces responses by inhibiting adaptive immune resistance. Nature. 2014;515:568-71.

16. Topalian SL, Sznol M, McDermott DF, Kluger HM, Carvajal RD, Sharfman WH, et al. Survival, durable tumor remission, and longterm safety in patients with advanced melanoma receiving nivolumab. J Clin Oncol. 2014;32:1020-30.

17. Hou JY, Baptiste C, Hombalegowda RB, Tergas AI, Feldman R, Jones NL, et al. Vulvar and vaginal melanoma: a unique subclass of mucosal melanoma based on a comprehensive molecular analysis of 51 cases compared with 2253 cases of nongynecologic melanoma. Cancer. 2017;123:1333-44.

18. Saleh B, Kriegsmann J, Falk S, Aulmann S. Frequent PD-L1 Expression in Malignant Melanomas of the Vulva. Int J Gynecol Pathol. 2018;37:477-81.

19. Kaunitz GJ, Cottrell TR, Lilo M, Muthappan V, Esandrio J, Berry $\mathrm{S}$, et al. Melanoma subtypes demonstrate distinct PD-L1 expression profiles. Lab Invest. 2017;97:1063-71.

20. Chłopik A, Selim MA, Peng Y, Wu C-L, Tell-Marti G, Paral KM, et al. Prognostic role of tumoral PDL1 expression and peritumoral FoxP3+ lymphocytes in vulvar melanomas. Hum Pathol. 2018;73:176-83. 
21. Shoushtari AN, Munhoz RR, Kuk D, Ott PA, Johnson DB, Tsai $\mathrm{KK}$, et al. The efficacy of anti-PD-1 agents in acral and mucosal melanoma. Cancer. 2016;122:3354-62.

22. Alvino E, Passarelli F, Cannavò E, Fortes C, Mastroeni S, Caporali S, et al. High expression of the mismatch repair protein MSH6 is associated with poor patient survival in melanoma. Am J Clin Pathol. 2014;142:121-32.

23. Lee WJ, Lee YJ, Shin HJ, Won CH, Chang SE, Choi JH, et al. Clinicopathological significance of tumor-infiltrating lymphocytes and programmed death-1 expression in cutaneous melanoma: a comparative study on clinical subtypes. Melanoma Res. 2018;28:423-34.

24. Kluger H, Zito CR, Barr M, Baine M, Chiang VL, Sznol M, et al. Characterization of PD-L1 expression and associated $\mathrm{T}$ cell infiltrates in metastatic melanoma samples from variable anatomic sites. Clin Cancer Res. 2015;12:3052-60.

25. Teng MW, Ngiow SF, Ribas A, Smyth MJ. Classifying cancers based on T-cell infiltration and PD-L1. Cancer Res. 2015;75:2139-45.

26. Taube JM, Klein AP, Brahmer JR, Xu H, Pan X, Kim JH, et al. Association of PD-1, PD-1 ligands, and other features of the tumor immune microenvironment with response to anti-PD-1 therapy. Clin Cancer Res. 2014;20:5064-74.

27. Le DT, Durham JN, Smith KN, Wang H, Bartlett BR, Aulakh LK, et al. Mismatch repair deficiency predicts response of solid tumors to PD-1 blockade. Science. 2017;357:409-13.

28. Kubeček O, Kopecký J. Microsatellite instability in melanoma: a comprehensive review. Melanoma Res. 2016;26:545-50.

29. Castiglia D, Bernardini S, Alvino E, Pagani E, De Luca N, Falcinelli S, et al. Concomitant activation of Wnt pathway and loss of mismatch repair function in human melanoma. Genes Chromosomes Cancer. 2008;47:614-24.

30. Palmieri G, Ascierto PA, Cossu A, Colombino M, Casula M, Botti $\mathrm{G}$, et al. Assessment of genetic instability in melanocytic skin lesions through microsatellite analysis of benign naevi, dysplastic naevi, and primary melanomas and their metastases. Melanoma Res. 2003;13:167-70.

31. Dhillon AS, Hagan S, Rath O, Kolch W. MAP kinase signalling pathways in cancer. Oncogene. 2007;26:3279-90.

32. van Engen-van Grunsven AC, Küsters-Vandevelde HV, De Hullu J, van Duijn LM, Rijntjes J, Bovée JV, et al. NRAS mutations are more prevalent than KIT mutations in melanoma of the female urogenital tract-a study of 24 cases from the Netherlands. Gynecol Oncol. 2014;134:10-4.

33. Tseng D, Kim J, Warrick A, Nelson D, Pukay M, Beadling C, et al. Oncogenic mutations in melanomas and benign melanocytic nevi of the female genital tract. J Am Acad Dermatol. 2014;71:229-36.

34. Ponti G, Manfredini M, Greco S, Pellacani G, Depenni R, Tomasi A, et al. BRAF, NRAS and C-KIT advanced melanoma: clinicopathological features, targeted-therapy strategies and survival. Anticancer Res. 2017;37:7043-8.

35. Long GV, Wilmott JS, Capper D, Preusser M, Zhang YE, Thompson JF, et al. Immunohistochemistry is highly sensitive and specific for the detection of V600E BRAF mutation in melanoma. Am J Surg Pathol. 2013;37:61-5.

36. Wong CW, Fan YS, Chan TL, Chan AS, Ho LC, Ma TK, et al. BRAF and NRAS mutations are uncommon in melanomas arising in diverse internal organs. J Clin Pathol. 2005;58:640-4.

37. Aulmann S, Sinn HP, Penzel R, Gilks CB, Schott S, Hassel JC, et al. Comparison of molecular abnormalities in vulvar and vaginal melanomas. Mod Pathol. 2014;27:1386-93.

38. Seifried S, Haydu LE, Quinn MJ, Scolyer RA, Stretch JR, Thompson JF. Melanoma of the vulva and vagina: principles of staging and their relevance to management based on a clinicopathologic analysis of 85 cases. Ann Surg Oncol. 2015;22:1959-66.

39. Piura B. Management of primary melanoma of the female urogenital tract. Lancet Oncol. 2008;9:973-81.

40. Stamatelli A, Saetta AA, Bei T, Kavantzas N, Michalopoulos NV, Patsouris E, et al. B-Raf mutations, microsatellite instability and p53 protein expression in sporadic basal cell carcinomas. Pathol Oncol Res. 2011;17:633-7.

41. Vaysse C, Pautier P, Filleron T, Maisongrosse V, Rodier J-F, Lavoue $\mathrm{V}$, et al. A large retrospective multicenter study of vaginal melanomas: implications for new management. Melanoma Res. 2013;23:138-46.

42. Haiducu ML, Hinek A, Astanehe A, Lee TK, Kalia S. Extracutaneous melanoma epidemiology in British Columbia. Melanoma Res. 2014;24:377-80.

43. Üzüm N, Köse F, Ataoğlu Ö. Metastatic malignant melanoma of the uterine cervix: First diagnosed on liquid-based cytology. Diagn Cytopathol. 2008;36:769-72.

44. Deshpande AH, Munshi MM. Primary malignant melanoma of the uterine cervix: report of a case diagnosed by cervical scrape cytology and review of the literature. Diagn Cytopathol. 2001;25:108-11.

45. Lee JH, Yun J, Seo J-W, Bae G-E, Lee J-W, Kim SW. Primary malignant melanoma of cervix and vagina. Obstet Gynecol Sci. 2016;59:415-20.

46. Frumovitz M, Etchepareborda M, Sun CC, Soliman PT, Eifel PJ, Levenback CF, et al. Primary malignant melanoma of the vagina. Obstet Gynecol. 2010;116:1358-65.

47. Cobellis L, Calabrese E, Stefanon B, Raspagliesi F. Malignant melanoma of the vagina. A report of 15 cases. Eur J Gynaecol Oncol. 2000;21:295-7.

48. Udager AM, Frisch NK, Hong LJ, Stasenko M, Johnston CM, Liu JR, et al. Gynecologic melanomas: A clinicopathologic and molecular analysis. Gynecol Oncol. 2017;147:351-7.

49. Ditto A, Bogani G, Martinelli F, Di Donato V, Laufer J, Scasso S, et al. Surgical management and prognostic factors of vulvovaginal melanoma. J Low Genit Trac Dis. 2016;20:e24-e9.

50. Miner TJ, Delgado R, Zeisler J, Busam K, Alektiar K, Barakat R, et al. Primary vaginal melanoma: a critical analysis of therapy. Ann Surg Oncol. 2004;11:34-9.

51. Garbe C, Peris K, Hauschild A, Saiag P, Middleton M, Spatz A, et al. Diagnosis and treatment of melanoma. European consensusbased interdisciplinary guideline-Update 2012. Eur J Cancer. 2012;48:2375-90.

52. Ditto A, Bogani G, Martinelli F, Raspagliesi F. Treatment of genital melanoma: are we ready for innovative therapies? Int $\mathbf{J}$ Gynecol Cancer. 2017;27:1063.

53. Wong SL, Balch CM, Hurley P, Agarwala SS, Akhurst TJ, Cochran A, et al. Sentinel lymph node biopsy for melanoma: American Society of Clinical Oncology and Society of Surgical Oncology joint clinical practice guideline. Ann Surg Oncol. 2012;19:3313-24.

54. Janco JMT, Markovic SN, Weaver AL, Cliby WA. Vulvar and vaginal melanoma: case series and review of current management options including neoadjuvant chemotherapy. Gynecol Oncol. 2013;129:533-7.

55. Harting MS, Kim KB. Biochemotherapy in patients with advanced vulvovaginal mucosal melanoma. Melanoma Res. 2004; 14:517-20.

56. Serrone L, Zeuli M, Sega F, Cognetti F. Dacarbazine-based chemotherapy for metastatic melanoma: thirty-year experience overview. J Exp Clin Cancer Res. 2000;19:21-34.

57. Saito T, Tabata T, Ikushima $H$, Yanai $H$, Tashiro $H$, Niikura $H$, et al. Japan Society of Gynecologic Oncology guidelines 2015 for the treatment of vulvar cancer and vaginal cancer. Int $\mathrm{J}$ Clin Oncol. 2018;23:201-34. 
58. Schiavone MB, Broach V, Shoushtari AN, Carvajal RD, Alektiar $\mathrm{K}$, Kollmeier MA, et al. Combined immunotherapy and radiation for treatment of mucosal melanomas of the lower genital tract. Gynecol Oncol Rep. 2016;16:42-6.

59. Lipson EJ, Forde PM, Hammers HJ, Emens LA, Taube JM, Topalian SL. Antagonists of PD-1 and PD-L1 in Cancer Treatment. Semin Oncol. 2015;42:587-600.

60. Sunshine J, Taube JM. PD-1/PD-L1 inhibitors. Curr Opin Pharmacol. 2015;23:32-8.

61. Daud AI, Wolchok JD, Robert C, Hwu W-J, Weber JS, Ribas A, et al. Programmed death-ligand 1 expression and response to the anti-programmed death 1 antibody Pembrolizumab in melanoma. J Clin Oncol. 2016;34:4102.

62. Hino R, Kabashima K, Kato Y, Yagi H, Nakamura M, Honjo T, et al. Tumor cell expression of programmed cell death-1 ligand 1 is a prognostic factor for malignant melanoma. Cancer. 2010;116:1757-66.

63. Patel SP, Kurzrock R. PD-L1 expression as a predictive biomarker in cancer immunotherapy. Mol Cancer Ther. 2015;14:847-56.

64. Chan AWH, Tong JHM, Kwan JSH, Chow C, Chung LY, Chau SL, et al. Assessment of programmed cell death ligand-1 expression by 4 diagnostic assays and its clinicopathological correlation in a large cohort of surgical resected non-small cell lung carcinoma. Mod Pathol. 2018;31:1381-90.

65. Sunshine JC, Nguyen PL, Kaunitz GJ, Cottrell TR, Berry S, Esandrio J, et al. PD-L1 Expression in Melanoma: A Quantitative Immunohistochemical Antibody Comparison. Clin Cancer Res. 2017;23:4938-44.

66. Kerr KM, Hirsch FR. Programmed Death Ligand-1 Immunohistochemistry: Friend or Foe? Arch Pathol Lab Med. 2016;140:326-31.

67. Hirsch FR, McElhinny A, Stanforth D, Ranger-Moore J, Jansson M, Kulangara K, et al. PD-L1 Immunohistochemistry assays for lung cancer: results from phase 1 of the blueprint PD-L1 IHC assay comparison project. J Thorac Oncol. 2017;12:208-22.

68. D'Angelo SP, Larkin J, Sosman JA, Lebbe C, Brady B, Neyns B, et al. Efficacy and safety of nivolumab alone or in combination with ipilimumab in patients with mucosal melanoma: a pooled analysis. J Clin Oncol. 2017;35:226-35.

69. Robert C, Schachter J, Long GV, Arance A, Grob JJ, Mortier L, et al. Pembrolizumab versus Ipilimumab in advanced melanoma. N Engl J Med. 2015;372:2521-32.

70. Weber J, Mandala M, Del Vecchio M, Gogas HJ, Arance AM, Cowey CL, et al. Adjuvant Nivolumab versus Ipilimumab in Resected Stage III or IV Melanoma. N Engl J Med. 2017;377:1824-35.

71. Quereux G, Wylomanski S, Bouquin R, Saint-Jean M, Peuvrel L, Knol AC, et al. Are checkpoint inhibitors a valuable option for metastatic or unresectable vulvar and vaginal melanomas? J Eur Acad Dermatol Venereol. 2018;32:e39-e40.

72. Fridman WH, Galon J, Pagès F, Tartour E, Sautès-Fridman C, Kroemer G. Prognostic and predictive impact of intra-and peritumoral immune infiltrates. Cancer Res. 2011;71:5601-5.

73. Azimi F, Scolyer RA, Rumcheva P, Moncrieff M, Murali R, McCarthy SW, et al. Tumor-infiltrating lymphocyte grade is an independent predictor of sentinel lymph node status and survival in patients with cutaneous melanoma. J Clin Oncol. 2012;30:2678-83.

74. Saldanha G, Flatman K, Teo KW, Bamford M. A novel numerical scoring system for melanoma tumor-infiltrating lymphocytes has better prognostic value than standard scoring. Am J Surg Pathol. 2017;41:906-14.

75. Koelzer VH, Sirinukunwattana K, Rittscher J, Mertz KD. Precision immunoprofiling by image analysis and artificial intelligence. Virchows Arch 2019;474:511-22.
76. Yu K, Liu X, Jiang Z, Hu C, Zou F, Chen C, et al. Discovery of a highly selective KIT kinase primary V559D mutant inhibitor for gastrointestinal stromal tumors (GISTs). Oncotarget. 2017;8:111110-8.

77. Gajiwala KS, Wu JC, Christensen J, Deshmukh GD, Diehl W, DiNitto JP, et al. KIT kinase mutants show unique mechanisms of drug resistance to imatinib and sunitinib in gastrointestinal stromal tumor patients. Proc Natl Acad Sci USA. 2009;106:1542-7.

78. Noujaim J, Gonzalez D, Thway K, Jones RL, Judson I. p.(L576P)KIT mutation in GIST: Favorable prognosis and sensitive to imatinib? Cancer Biol Ther. 2016;17:543-5.

79. Nishida T, Kanda T, Nishitani A, Takahashi T, Nakajima K, Ishikawa $\mathrm{T}$, et al. Secondary mutations in the kinase domain of the KIT gene are predominant in imatinib-resistant gastrointestinal stromal tumor. Cancer Sci. 2008;99:799-804.

80. Roberts KG, Odell AF, Byrnes EM, Baleato RM, Griffith R, Lyons $\mathrm{AB}$, et al. Resistance to c-KIT kinase inhibitors conferred by V654A mutation. Mol Cancer Ther 2007;6:1159-66.

81. Spitaleri G, Biffi R, Barberis M, Fumagalli C, Toffalorio F, Catania $\mathrm{C}$, et al. Inactivity of imatinib in gastrointestinal stromal tumors (GISTs) harboring a KIT activation-loop domain mutation (exon 17 mutation pN822K). OncoTargets Ther. 2015;8:1997.

82. Ma Y, Cunningham ME, Wang X, Ghosh I, Regan L, Longley BJ. Inhibition of spontaneous receptor phosphorylation by residues in a putative $\alpha$-helix in the KIT intracellular juxtamembrane region. $\mathrm{J}$ Biol Chem. 1999;274:13399-402.

83. Curtin JA, Busam K, Pinkel D, Bastian BC. Somatic activation of KIT in distinct subtypes of melanoma. $J$ Clin Oncol. 2006;24:4340-6.

84. Rossi S, Gasparotto D, Toffolatti L, Pastrello C, Gallina G, Marzotto A, et al. Molecular and clinicopathologic characterization of gastrointestinal stromal tumors (GISTs) of small size. Am J Surg Pathol. 2010;34:1480-91.

85. Shain AH, Garrido M, Botton T, Talevich E, Yeh I, Sanborn JZ, et al. Exome sequencing of desmoplastic melanoma identifies recurrent NFKBIE promoter mutations and diverse activating mutations in the MAPK pathway. Nat Genet. 2015;47:1194.

86. Kong Y, Si L, Zhu Y, Xu XG, Corless CL, Flaherty K, et al. Large scale analysis of KIT aberrations in Chinese patients with melanoma. Clin Cancer Res. 2011;17:1684-91. clincanres. 2346.010

87. Cheng L, Lopez-Beltran A, Massari F, MacLennan GT, Montironi R. Molecular testing for BRAF mutations to inform melanoma treatment decisions: a move toward precision medicine. Mod Pathol. 2018;31:24-38.

88. Pappa KI, Vlachos GD, Roubelakis M, Vlachos D-EG, Kalafati TG, Loutradis D, et al. Low mutational burden of eight genes involved in the MAPK/ERK, PI3K/AKT, and GNAQ/11 pathways in female genital tract primary melanomas. Biomed Res Int. 2015;2015:303791.

89. Wylomanski S, Denis MG, Theoleyre S, Bouquin R, Vallee A, $\mathrm{Knol} \mathrm{AC}$, et al. BRAF mutations might be more common than supposed in vulvar melanomas. Exp Dermatol. 2018;27:210-3.

90. Anwar MA, Murad F, Dawson E, Abd Elmageed ZY, Tsumagari $\mathrm{K}$, Kandil E. Immunohistochemistry as a reliable method for detection of BRAF-V600E mutation in melanoma: a systematic review and meta-analysis of current published literature. J Surg Res. 2016;203:407-15.

91. Pearlstein MV, Zedek DC, Ollila DW, Treece A, Gulley ML, Groben PA, et al. Validation of the VE1 immunostain for the BRAF V600E mutation in melanoma. J Cutan Pathol. 2014;41:724-32.

92. Naboush A, Roman CA, Shapira I. Immune checkpoint inhibitors in malignancies with mismatch repair deficiency: a review of the state of the current knowledge. J Invest Med. 2017;65:754-8.

93. Roncati L. Microsatellite instability predicts response to anti-PD1 immunotherapy in metastatic melanoma. Acta Derm Croat. 2018;26:341-3. 